\title{
Developing services to support parents caring for a technology-dependent child at home
}

\author{
S. Kirk ${ }^{\star}$ and C. Glendinning $\dagger$ \\ ${ }^{*}$ School of Nursing, Midwifery and Health Visiting, University of Manchester, Manchester, and \\ $\uparrow$ Social Policy Research Unit, University of York, York, UK \\ Accepted for publication 14 October 2003
}

Keywords children with complex needs, home care, parent participation, interagency working, technologydependent children, professional support
Correspondence: Dr Susan Kirk, School of Nursing, Midwifery and Health Visiting, University of Manchester, Coupland 3, Oxford Road, Manchester M13 9 PL, UK

E-mail: sue.kirk@man.ac.uk

\begin{abstract}
Background A group of children with complex health care needs have emerged as a result of medical advances and government policies emphasizing the community as the arena for care. Some of these children remain dependent on the medical technology that enabled them to survive and require care of a complex and intensive nature to be carried out by their parents at home.

Aims To explore the experiences of families caring at home for a technology-dependent child; to examine their needs for practical and other support; and to examine how far services are currently meeting these needs.

Methods In-depth interviews were conducted with the parents of 24 technology-dependent children and with 44 health, social care and other professionals.

Results Services in the community were not sufficiently developed to support this group of families. Major problems were identified in the purchasing and provision of both short-term care/ home support services and specialist equipment/therapies in the community. Service provision could be poorly planned and co-ordinated at an operational level and few families had a designated key worker. Parents felt that professionals did not always recognize either the emotional costs entailed in providing care of this nature or their expertise in caregiving. Information-giving to parents was often described as poor and participants reported that hospital professionals failed to negotiate the transfer of caregiving responsibility to parents.

Conclusions Services need to work in partnership with families and with each other at both strategic and operational levels, to develop integrated and co-ordinated services that can meet the needs of this group of families.
\end{abstract}

\section{Introduction}

Medical advances in the care of preterm, congenitally impaired and seriously ill infants and children have led to the emergence of a group of children with complex health care needs who remain dependent on medical technology (Woodroffe et al. 1993; Draper 1995). Government policies to promote home rather than hospital-based care for children (Department of Health and Social Security 1976; Department of Health 1989, 1991; 1996) mean that intensive and specialized nursing care is now carried out in the home by parents (and, indeed, by older children themselves). Caring for 
such children in the community presents major challenges for health, social care and educational services in the UK. However, until very recently there has been a dearth of information on the experiences of their families or on the responses of statutory services and professionals. The study reported in this paper aimed to address this lack of research.

'Technology-dependent' is widely used in North America, and increasingly in the UK, to describe children:

who need both a medical device to compensate for the loss of a vital body function and substantial and ongoing nursing care to avert death or further disability. (Wagner et al. 1988, p. 3)

However, this is a diverse population, varying in the types (and numbers) of technologies involved, the intensity and timing of the nursing they need, whether they have additional disabilities and their longer-term prognosis (Wagner et al. 1988; Glendinning et al. 2001). The devices on which children may depend range from the 'high tech' (e.g. a mechanical ventilator) to the relatively 'low tech' (e.g. a colostomy). Most published research (including this study) focuses on children dependent on 'high tech' medical technologies.

Existing studies (largely from North America) have documented the considerable social, emotional and financial impacts on parents of caring for a technology-dependent child (Young et al. 1988; Aday et al. 1989; Jennings 1990; McKeever 1991; Leonard et al. 1993; Teague etal. 1993; Patterson et al. 1994; Kirk 1998; Townsley \& Robinson 2000). Parents can experience difficulties in obtaining a break from caring because of the lack of appropriate services (Diehl et al. 1991; Wheeler \& Lewis 1993; Youngblut et al. 1994; Petr et al. 1995). Establishing relationships in which professionals recognize the expertise that parents possess in caring for their children has also been found to be problematic (Young et al. 1988; Aday et al. 1989; Diehl et al. 1991; McKeever 1991).

The numbers of technology-dependent children in the UK are unknown, nor is there currently any sound basis from which to derive reliable estimates.
Available information suggests that technologydependent children may be disproportionately young (under 2 years old) and there may be major regional variations in their prevalence (Glendinning et al. 1999, 2001). This paper summarizes and brings together the findings of the first comprehensive UK study to explore parents' experiences of caring for a technology-dependent child, the perceptions of the professionals supporting them in the home and the implications for statutory services ( Kirk 1999, 2001; Kirk \& Glendinning 1999, 2002).

\section{Research design and methods}

The study aimed to:

- explore the experiences of families caring at home for a technology-dependent child; and

- identify perceived problems and good practice in the purchasing, delivery and co-ordination of services.

\section{Sampling}

Twenty-four families were recruited via three specialist children's hospitals in the north of England with the assistance of nurse specialists and hospital consultants. Families were initially purposively sampled to incorporate a range of different family/ child characteristics but as the analysis progressed they were theoretically sampled. The sample size was determined by the time period allowed for data collection and by theoretical saturation. Thirty-eight professionals were purposively sampled from a list of all those currently in contact with the families. In addition, as part of a small longitudinal discharge study, three families whose children were awaiting hospital discharge at the start of the study were purposively sampled as well as the professionals leading the discharge planning process and the associated local service commissioners $(n=6)$.

\section{Sample characteristics}

In total, 23 mothers and 10 fathers were interviewed, all but one of the latter as part of a joint 
interview with both parents. Four families were headed by lone mothers. The children were dependent on a range of medical technologies, many on more than one (Tables 1 and 2). Table 2 provides further details of the children's characteristics. The sample of professionals consisted of 38 individuals from a range of professional groups, three health authority purchasers and three nurses with a hospital discharge planning role (Table 3).

\section{Data collection}

Face-to-face, in-depth interviews were conducted with participants. All interviews with parents took place in the family home apart from two interviews in the discharge study, which were conducted in hospital. The interviews with professionals were conducted at their place of work and with home carers in their own homes. Broad, open-ended questions were used to elicit information from participants with the researcher probing for further detail. Interview guides were used for the general direction of the interviews but participants were encouraged to direct the conversation into areas of importance for them. Questions became more focused and specific as analysis progressed and the key issues emerged. All interviews apart from two were tape-recorded and transcribed verbatim. Detailed notes were taken during the non-taperecorded interviews.

\section{Data analysis}

Principles and procedures of the constant comparative method as outlined by Glaser (1992) and Strauss \& Corbin (1998) guided data analysis. Concurrent data collection and analysis occurred with

Table 1. The technological dependencies of the children in the sample $(n=24)$

\begin{tabular}{lc}
\hline Technological dependence & Number \\
\hline Tracheostomy & 10 \\
Oxygen therapy & 8 \\
Mechanical ventilation & 6 \\
Intravenous drugs & 4 \\
Parenteral nutrition & 2 \\
Peritoneal dialysis & 2 \\
Others (e.g.gastrostomy) & 13 \\
\hline
\end{tabular}

codes and categories being inductively developed from the data. Transcripts were coded line by line using the NUD*IST (Non-numerical Unstructured Data Indexing Searching Theory Building) computer program (Qualitative Solutions and Research 1997). Analysis involved identifying codes and their properties and dimensions, grouping the codes to create categories, systematically comparing and contrasting the codes and categories and examining the connections between the categories and subcategories.

Table 2. Characteristics of the children in the sample $(n=24)$

\begin{tabular}{lc}
\hline Characteristic & Number \\
\hline Gender & \\
$\quad$ Male & 13 \\
$\quad$ Female & 11 \\
Age & 12 \\
$\quad<5$ years & 6 \\
$5-11$ years & 5 \\
$12-18$ years & \\
Duration of technology dependence & 13 \\
$\quad$ Since birth & 11 \\
Following birth & \\
Number of technologies on which the & \\
children were dependent & 6 \\
1 & 15 \\
2 & 3 \\
3 & \\
Length of time since discharge & 8 \\
$<1$ years & 11 \\
$1-3$ years & 1 \\
$4-6$ years & 1 \\
$7-9$ years & 2 \\
$\geq 10$ years & \\
Education $(n=11)$ & 8 \\
Mainstream school & 3 \\
Special school & \\
\hline
\end{tabular}

Table 3. The sample of professionals $(n=44)$

\begin{tabular}{ll}
\hline Professional & Number \\
\hline Clinical nurse specialists & 7 \\
Community children's nurses & 5 \\
Health visitors & 5 \\
District nurses & 4 \\
Home carers & 4 \\
General practitioners & 4 \\
Community-based social workers & 4 \\
Community paediatricians & 3 \\
Hospital social workers & 3 \\
School head teachers/teachers & 2 \\
Health authority purchasers & 3 \\
\hline
\end{tabular}




\section{Ensuring rigour}

Regular meetings were held between the coauthors throughout the fieldwork and the analysis. A number of transcripts and the analytical coding were jointly reviewed as a means of enhancing theoretical sensitivity, uncovering any biases and clarifying the interpretation of the data. At all stages of the study the researchers critically reflected on, and took into account, their influence on the study through their assumptions, actions, feelings and relationships with participants. An audit trail outlined the research and the decision-making processes and the evolution of the coding and analysis was recorded in memos and the ongoing record of the developing NUD ${ }^{\star}$ IST tree structure. Field notes record the interview process and interview transcripts and audio-tapes are available. Data were examined for rival explanations and negative cases identified and examined to identify the reasons for difference. The use of theoretical sampling maximized the range of information obtained.

\section{Ethical issues}

Each family was contacted by hospital staff to provide information about the research and obtain their consent to pass the families details on to the researcher. At the interview written informed consent was obtained. Approval was obtained from four local research ethics committees. Professionals received a letter containing information about the study before telephone contact to discuss their willingness to participate and to arrange an interview. All participants were assured of confidentiality and anonymity.

Names were not used on data tapes or interview transcripts. Participants were assigned a code and/ or pseudonym that was used on all data tapes, transcripts and data extracts. Data tapes were kept in a locked filing cabinet and transcripts on a computer that was accessible only via a password system. Any identifiable information was removed from transcripts at the earliest opportunity. Participants' names and their assigned code numbers/pseudonyms were not kept on the computer with the transcripts.

\section{Research findings}

This section will firstly present the findings that describe how families experienced caring at home for a technology-dependent child and the impact that it had on their lives. This will be followed by parents' and professionals' perspectives on the provision of support in the community, highlighting the problems and the good practice they identified.

\section{The experience of caring for a technology- dependent child}

In caring for their children at home, parents had also assumed responsibility for the performance of highly technical procedures that would formerly have only been undertaken by qualified professionals. However, parents often felt that their assumption of these responsibilities had not been openly negotiated (Kirk 2001). Instead, the desire to have their child discharged home had dominated. The professionals in contact with parents were also concerned that hospital staff had not explicitly discussed with parents their responsibility for clinical procedures but had unquestioningly expected parents to continue participating in their child's care as they had done in hospital. Moreover, for many families there was no alternative to assuming the main responsibility for their child's nursing and technical care, as local health and social services were unable to provide the type or level of care required.

Parents performed multiple roles, including managing their child's condition, organizing services and advocating for their child, as well as the more usual elements of parenting. Regular clinical procedures included changing tracheostomy tubes, suctioning airways, and administering intravenous infusions and feeds. Some of these procedures were painful for the child and involved direct physical restraint, both of which caused parents distress:

The NG tube, you've got to get it up and wriggle it down, and he's crying and he's dead distressed, and it'll go the wrong way 
or curl in his mouth. You end up in tears and he ends up in tears.

Some parents felt these emotional aspects of caregiving were neglected by professionals, who emphasized only the acquisition of technical competencies when teaching parents.

Parents had to make complex judgements about their child's condition, for example, by adjusting dosages according to their assessment of their child's condition. The monitoring and associated clinical procedures could dominate their lives, leading them sometimes to question whether they were parents or nurses. However, unlike professional nurses they described how there had been no choice about taking the job or having any entitlement to time off.

Advocacy by parents was often required to ensure children obtained appropriate services. Parents could spend a considerable amount of time organizing and co-ordinating services and ensuring that they had sufficient equipment and supplies to care for their child. These responsibilities could cause additional stress:

I think the thing that I feel would have been helpful would have been somebody, it's alright people think that you're a parent, you're just here to care for your child whatever happens, to fight for what they need, but a lot of the time I felt that I was the kingpin in what was happening, people were asking me ... I felt that I was the person coordinating all the care and it was a megaweight when you're under stress ... it gets a heavy load to carry.

\section{The impact on families}

Families' lives often revolved around the technology and the routines it imposed:

Everything just revolved around this trachie, it was awful. Perhaps we had the wrong attitude in that we let it dominate our lives.

Home environments became medicalized by the presence of equipment, staff employed to support parents at home and frequent visits from other professionals. Sleep was often disrupted by machine alarms going off; the need to administer medications or other treatments during the night; and, in some cases, the need to be constantly vigilant over their child. Feelings of anxiety, stress and exhaustion were frequently reported. However, parents made a determined effort not to allow their lives to be dominated by the demands of the technology and over time incorporated this into a more balanced way of life.

Social activities were often restricted by heavy and cumbersome equipment or the need to return home to start overnight therapies. When they did venture outside the house, parents had to contend with public reactions to the child; their embarrassment was increased if they had to perform procedures such as suctioning airways or administering gastrostomy feeds in public. Holidays had to be well organized and parents often chose destinations near a hospital that they knew could provide support in an emergency.

Otherwise, it was difficult for parents to have a break, as the child's specialized needs meant that usual babysitters - family members or friends were inappropriate unless they had also received special training. Some parents felt the inability to spend time together as a couple had placed a strain on their relationship. Siblings were also thought to have missed out on parents' attention and other opportunities. Caring for a technologydependent child also had a financial impact; some parents had given up work to care for the child and had to cope with a reduced income at a time when household costs had increased, for example, because of more laundry, heating and electricity supplies for equipment such as infusion pumps and ventilators.

\section{Short-term care and home support services}

Because relatives and friends often could not help with childcare unless they had been trained, parents relied on formal services to provide a break from caring. However, both parents and professionals described how accessing such support was one of the biggest problems families faced. Usual short-term care or home-based support services 
were inappropriate because of the child's specialized nursing needs. Consequently, home care workers were often specially recruited and trained to support families at home (and sometimes the child at school), by providing a regular break during the day and/or overnight. This support could be required round-the-clock, if children had particularly intensive care needs. Other sources of help at home came from district nursing auxillaries, Marie Curie nurses, voluntary agency workers, agency nurses, foster carers and family aides. However, the levels and sources of help with home care seemed to be determined more by the area the family lived in than their needs or those of the child.

Disputes between health and local authorities over responsibility for funding short-term care and home support workers were repeatedly reported by both parents and professionals. In most areas it was not clear where responsibilities lay, so different local interpretations led to different patterns of services. Disputes were exacerbated because some localities had no previous experience of supporting children with such specialized and intensive needs and so lacked established procedures for commissioning services. Funding disputes could take considerable time to resolve, creating additional stress for parents and delaying hospital discharge. In two localities where the National Health Service (NHS) and local authority had agreed to contribute equally to funding home care packages, professionals felt this had significantly speeded up hospital discharge.

Home-based care involved a loss of privacy for families. However, parents preferred this to institutionally based facilities such as children's hospices or hospitals, because it was more flexible; the child remained in a familiar environment; bulky equipment did not need transporting; risks of cross-infection were reduced; and carers were familiar with and trusted by the child and parents alike. Parents did not object to home care staff without professional qualifications, so long as they were familiar with the child and her/his treatment. Indeed, many parents thought they would be unable to sustain caring for their child at home without the support of home carers.

\section{Supplying equipment and medication at home}

The children needed large and expensive pieces of equipment such as ventilators; and ongoing supplies of consumables such as suction catheters, tracheostomy tubes and drug products (e.g. antibiotics, oxygen and nutrient solutions). Again, disputes between health authorities, NHS hospital and community trusts and general practitioners (GPs) over responsibilities for providing these were frequently reported and health professionals spent considerable time and effort securing agreement on their funding and supply. Disputes and delays over the supply of equipment and consumables for children on mechanical ventilation, tracheostomy, oxygen therapy and enteral feeding were far more common than for those dependent on peritoneal dialysis, intravenous drugs and parenteral nutrition, for whom funding responsibilities seemed clearer.

The arrangements for supplying consumables to families varied widely. GPs, community and hospital pharmacists, clinical nurse specialists (CNSs), community children's nurses, district nurses, health visitors and commercial companies were all involved. For many families the supply of consumables was fragmented between two or more providers. Problems were particularly common when consumables were supplied by local primary and community health services and caused considerable stress for parents. In contrast, when a commercial company delivered supplies directly to parents, they were more likely to report a reliable and efficient service.

Community-based nurses confirmed these problems over the supply of equipment and consumables. The specialized equipment the children needed was not usually stocked by community equipment stores and if there was no specialist community children's nursing service, there was sometimes no one locally with expertise in equipment suitable for children - particularly children with very specialized needs which changed as they grew and their medical condition fluctuated. Community-based health professionals also expressed frustration that hospitals did not always give them sufficient time to order equipment that a child would need at home following discharge. 


\section{Planning and co-ordinating multiagency services}

In some cases discharge planning had commenced early, with parents and community professionals fully involved in planning the family's immediate and future needs. However, several community nurses felt they had not been adequately involved or given sufficient time by the hospital to arrange local services and equipment. Subsequent, postdischarge multidisciplinary meetings were reported by parents and professionals to be rare unless there was a crisis or statutory requirement (e.g. child protection concerns or educational review) and some parents reported they had not been invited to such meetings. Forward planning of children's educational needs was particularly poor and health professionals noted that home support services could not be arranged in a crisis because of the lengthy processes of recruiting and training carers.

Families often received services from a number of different organizations and professionals, yet these rarely appeared co-ordinated. Poor coordination could lead parents to feel overloaded with visits from professionals, with little time to establish a sense of a 'normal' family life and confused about the responsibilities of different professionals. Even professionals themselves were sometimes unclear about their responsibilities; both GPs and nurses were unsure whether GPs or hospital consultants were medically responsible for children while at home. Written information setting out the roles of individual professionals would have been valued by parents and professionals alike.

Professional roles were clearer in relation to specialist nursing services; CNSs based at the specialist hospital had a clearer sense than other professionals of their roles vis-à-vis both parents and other community nurses. However, even this varied, depending on the distance between the family home and the hospital; sometimes CNSs provided direct support to families but in other cases they acted as a resource of specialist expertise for local nurses. Conversely, health visitors and district nurses provided valuable information about local facilities and resources to more specialist CNSs and community children's nurses.
Both parents and professionals reported poor communications across the hospital-community interface; community health professionals were not always informed of readmissions, discharges or new treatment regimes. Communication problems were also reported between hospitals (many children received treatment from more than one hospital) and between community professionals.

Few families had a designated person whose role was to ensure communication and co-ordination between services, although both professionals and parents considered this very important. Parents felt there was sometimes an over-reliance on them to pass information between professionals and many parents became their own service co-ordinators. However, there were occasions when professionals worked closely together, jointly visiting home and school to provide information and training. Coordinating their visits reduced family intrusion and enhanced parents' feelings of support. The involvement of hospital liaison nurses, shared information systems and regular face-to-face contact between professionals was felt to improve communication.

\section{Receiving and providing support}

Unusually, families caring for a technology-dependent child often had considerably more specialist knowledge than the community-based professionals they encountered and this altered parentprofessional relationships. Some parents felt primary and community health professionals, in particular, could be threatened by their specialist expertise. However, parents valued professionals who admitted the limitations of their knowledge; this honesty provided the basis for a trusting relationship. In contrast, parents' own expertise was not always acknowledged by professionals and parents described instances when their views had been ignored or dismissed. Continuity in parentprofessional relationships was important in developing trust and mutual understanding of respective expertise.

There was remarkable consistency between parents' and professionals' views of the types of support valued by families (Kirk \& Glendinning 2002). Parents were reassured by having an accessible and reliable person who knew their child, who they 
could approach when they needed help, advice or information - someone who 'was there for them'. This promoted parental confidence and aided coping. Parents also valued being able to express their feelings and concerns; and receiving acknowledgement of their expertise and positive feedback on their care of the child. Being offered (rather than having to ask for) information enhanced parents' sense of control. However, too often parents had to seek out information for themselves, or received insufficient or conflicting advice which left them confused. The practical support, advice and advocacy offered by CNSs was identified as being particularly important. Again, these views were endorsed by professionals.

\section{Conclusions}

Although there are many similarities between the experience of caring for a technology-dependent child and that of a chronically ill or disabled child, the health care and nursing needs of the former group are undoubtedly more specialized, complex and intensive (Kirk 1998). The findings from this study suggest that the development of appropriate community-based services has not kept pace with the medical and technological advances that now allow children with complex, intensive needs to be discharged from hospital.

In this study the roles of professionals focused on supporting parental caregiving rather than providing 'hands-on' care. However, the potential to exploit parents was evident. Transferring responsibility for the provision of clinical care was rarely negotiated with parents before discharge and although they had a strong desire to care for their child at home, their choices were constrained to some extent by the lack of alternatives to parental caregiving. Appropriate and flexible home support services are not readily available and the funding and supply of equipment, consumables and medications is fragmented and poorly organized. CNSs and community children's nursing teams are not universally available. The complex web of multiagency services involved is often poorly planned and co-ordinated.

Caring for technology-dependent children in the community requires a multiagency approach to planning and funding services, with good interprofessional collaboration at operational levels. This approach is now at the heart of health and social care policies in the UK; NHS organizations have a duty to work in partnership (Department of Health 1997) and structural barriers to collaboration have been relaxed (Department of Health 1998a). Using the flexibilities in the 1999 Health Act to pool budgets could remove disputes over funding responsibilities and enable complex packages of services to be constructed for individual families. So far, however, services for children with complex needs have not featured prominently amongst schemes using the flexibilities (Glendinning et al. 2002). The Carers Grant (Department of Health 1999) or using the Direct Payments scheme (Department of Health 2001) could similarly enable parents to arrange flexible short-term 'breaks', although specialist training for substitute carers would still be required.

Above all, most families lacked a designated key worker to co-ordinate the delivery of services, to be a point of contact between parents and the service system and to ensure the overall planning and evaluation of services. This has long been advocated by independent research and government reports (Department of Health and Social Security 1976; Glendinning 1986; Thornes 1993; Audit Commission 1994; Department of Health 1998b) but has largely failed to be introduced (Sloper \& Turner 1992; Beresford 1995). This long-overdue development would do much both to improve the effectiveness of services and to support parents in the care of their children.

When working with this group of families professionals need to recognize parent's particular knowledge and expertise in providing specialized nursing care and value their active participation in their child's care. Moreover, it is important that professionals are aware that learning and providing care of this nature for their child has a substantial emotional dimension for parents and does not only involve the competent performance of a set of psychomotor skills. Parents should be given the opportunity to discuss their feelings about providing care of this nature for their own child. There is a need to remember that they are parents first and 
foremost, not nurses or care workers, and that they may need support in developing and sustaining a parenting role with their child.

\section{Acknowledgements}

The researchers would like to thank the research participants who so willingly gave their time to share their experiences with the researcher and the nurse specialists and consultant paediatricians who assisted us with recruiting the study families.

The study reported here was commissioned by the Department of Health as part of the 'Supporting Parenting' research initiative. However, the views expressed in this paper are those of the authors alone.

\section{References}

Aday, L. A., Wegener, D. H., Anderson, R. \& Aitkin, M. (1989) Home care for ventilator assisted children.

Health Affairs, 8, 137-147.

Audit Commission (1994) Seen but Not Heard: Coordinating Community Child Health and Social Services for Children. HMSO, London, UK.

Beresford, B. (1995) Expert Opinions: A National Survey of Parents Caring for a Severely Disabled Child. Policy Press, Bristol, UK.

Department of Health (1989) Caring for People: Community Care in the Next Decade and Beyond. HMSO, London, UK.

Department of Health (1991) Welfare of Children and Young People in Hospital. HMSO, London, UK.

Department of Health (1996) Child Health in the Community: a Guide to Good Practice. Department of Health, London, UK.

Department of Health (1997) The New NHS. Modern. Dependable, Cm 3807. The Stationery Office, London, UK.

Department of Health (1998a) Partnership in Action: New Opportunities for Joint Working Between Health and Social Services. Department of Health, London, UK.

Department of Health (1998b) Evaluation of the Pilot Project Programme for Children with Life-Threatening Illnesses. Department of Health, London, UK.

Department of Health (1999) Caring About Carers: A National Strategy for Carers. Department of Health, London, UK.

Department of Health (2001) Carers and Disabled Children Act 2000: Carers and People with Parental Respon- sibility for Disabled Children - Policy Guidance. Department of Health, London, UK.

Department of Health and Social Security (1976) Fit for the Future. The report of the committee on child health service (Court Report) Cmnd 6684.

Diehl, S., Moffitt, K. \& Wade, S. M. (1991) Focus group interviews with parents of children with medically complex needs: an intimate look at their perceptions and feelings. Children's Health Care, 20, 170-178.

Draper, G. (1995) Cancer. In: The Health of Our Children: Decennial Supplement (ed. B. Botting). Office for Population Censuses and Surveys, London, UK.

Glaser, B. (1992) Emergence Versus Forcing: Basics of Grounded Theory Analysis. Sociology Press, Mill Valley, CA, USA.

Glendinning, C. (1986) A Single Door; Social Work with the Families of Disabled Children. Allen and Unwin, Hemel Hempstead, UK.

Glendinning, C., Hudson, B., Hardy, B. \& Young, R. (2002) National Evaluation of Sites Using the s31 Flexibilities in the Health Act 1999. Final Project Report. National Primary Care Research and Development Centre, Manchester and Nuffield Institute for Health, Leeds, UK.

Glendinning, C., Kirk, S., Guiffrida, A. \& Lawton, D. (2001) Technology dependent children in the community: definitions, numbers and costs. Child: Care, Health and Development, 27, 321-334.

Glendinning, C. \& Kirk, S. with Guiffridda, A. \& Lawton, D. (1999) The Community-Based Care of TechnologyDependent Children in the UK: Definitions, Numbers and Costs. Research Report Commissioned by the Social Care Group at the Department of Health. National Primary Care Research and Development Centre, University of Manchester.

Jennings, P. (1990) Caring for a child with a tracheostomy. Nursing Standard 4 (30), 24-26; and 4 (32), 3840.

Kirk, S. (1998) Families experiences of caring at home for a technology-dependent child: a review of the literature. Child: Care, Health and Development, 24, 101114.

Kirk, S. (1999) Caring for children with specialised health care needs in the community: the challenges for primary care. Health and Social Care in the Community, 7, 350-357.

Kirk, S. (2001) Negotiating lay and professional roles in the care of children with complex health care needs. Journal of Advanced Nursing, 34, 593-602.

Kirk, S. \& Glendinning, C. (1999) Supporting Parents Caring for Technology-Dependent Child. Research Report. National Primary Care Research and Development Centre, University of Manchester.

Kirk, S. \& Glendinning, C. (2002) Supporting 'expert' 
parents - professional support and families caring for a child with complex health care needs in the community. International Journal of Nursing Studies, 39, 325335.

Leonard, B., Brust, J. D. \& Nelson, R. (1993) Parental distress: caring for medically fragile children. Journal of Pediatric Nursing, 8, 22-30.

McKeever, P. (1991) Mothering chronically-ill technology-dependent children: an analysis using critical theory. PhD Thesis. York University, Toronto, Canada.

Patterson, J., Jernell, J., Leonard, B. \& Titus, J. C. (1994) Caring for medically fragile children at home: the parent professional relationship. Journal of Pediatric Nursing, 9, 98-106.

Petr, C. G., Murdock, B. \& Chapin, R. (1995) Home care for children dependent on medical technology: the family perspective. Social Work in Health Care, 21, 522.

Qualitative Solutions and Research (1997) QSR NUD ${ }^{\star} I S T$. Version 4. [Windows]. Qualitative Solutions and Research, Melbourne, Australia.

Sloper, P. \& Turner, S. (1992) Service needs of families of children with severe physical disability. Child: Care, Health and Development, 18, 2592-2582.

Strauss, A. \& Corbin, J. (1998) Basics of Qualitative Research: Techniques and Procedures for Developing Grounded Theory, 2nd edn. Sage, Thousand Oaks, CA, USA.
Teague, B. R., Fleming, J., Castle, A., Kiernan, B., Lobo, M., Riggs, S. \& Wolfe, J. (1993) High tech home care for children with chronic health conditions: a pilot study. Journal of Pediatric Nursing, 8, 226-232.

Thornes, R. (1993) Bridging the Gaps: An Exploratory Study of the Interfaces between Primary and Specialist Care for Children within the Health Service. Action for Sick Children, London, UK.

Townsley, R. \& Robinson, C. (2000) Food for Thought: Effective Support for Families Caring for a Child Who is Tube Fed. Doveton Press, Norah Fry Research Centre, University of Bristol, Bristol, UK.

Wagner, J., Power, E. J. \& Fox, H. (1988) TechnologyDependent Children: Hospital versus Home Care. Office of Technology Assessment Task Force, J.P Lippincott, Philadelphia, PA, USA.

Wheeler, T. \& Lewis, C. C. (1993) Home care for medically fragile children: urban versus rural settings. Issues in Comprehensive Paediatric Nursing, 16, 13-30.

Woodroffe, C., Glickman, M., Barker, M. \& Power, C. (1993) Children, Teenagers and Health: the Key Data. Open University Press, Buckingham, UK.

Young, L., Creighton, D. \& Sauve, R. (1988) The needs of families of infants discharged home with continuous oxygen therapy. Journal of Obstetric, Gynaecological and Neonatal Nursing, 17, 187-193.

Youngblut, J., Brennan, P. \& Swegart, L. (1994) Families with medically fragile children: an exploratory study. Pediatric Nursing, 20, 463-468. 